\title{
NEURITE APÓS A INSTALAÇÃO DE IMPLANTE: RELATO DE CASO
}

Aline Monise SEBASTIANI, Paulo Afonso CUNALI, Aguinaldo FARIAS, Rayza Santiago WAPNIARZ, Daniel BONOTTO

As dores neuropáticas são oriundas do Sistema Nervoso Central ou Periférico, sendo classificadas em episódicas e contínuas (LUND, 2002). Se manifestam sob a forma de dor facial crônica, geralmente contínua, profunda, mal localizada e de intensidade baixa a moderada com episódios de intensa dor, com características de choque ou queimação (LOZANO, 2010). Danos a qualquer dos ramos do nervo trigêmio podem causar alterações sensoriais. A Neurite é uma dor neuropática contínua que resulta de trauma nervoso associado com pressão, desaferentação, amputação ou infecção. A cirurgia de implante é uma das causas mais comuns de lesão nervosa em pacientes odontológicos (PARK, 2009). Paciente do gênero feminino, 42 anos, foi atendida na Especialização de DTM da UFPR com queixa de dor contínua, em queimação e choque, na região de corpo mandibular esquerdo, iniciada após cirurgia de implante na região do dente 35 , há 2 anos. A tomografia computadorizada da região comprovou a porção apical do implante dentro do canal mandibular. O controle foi realizado com gabapentina, 900mg/dia. Após 6 meses de tratamento, a melhora subjetiva foi de $60 \%$ para dor, com prognóstico duvidoso. Pela sua relação etiológica com procedimentos cirúrgicos, é importante que o cirurgião-dentista esteja atento às dores neuropáticas orofaciais.

Palavras-chave: implantes dentários; dor facial; neurite. 